Article

\title{
Bactericidal Effect of Lauric Acid-Loaded PCL-PEG-PCL Nano-Sized Micelles on Skin Commensal Propionibacterium acnes
}

\author{
Thi-Quynh-Mai Tran 1,2, Ming-Fa Hsieh 1,2,3,*, Keng-Lun Chang ${ }^{2}$, Quoc-Hue Pho ${ }^{2}$, \\ Van-Cuong Nguyen ${ }^{4}$, Ching-Yi Cheng ${ }^{5}$ and Chun-Ming Huang ${ }^{6}$ \\ 1 International Master Program of Biomedical Material and Technology, Chung Yuan Christian University, \\ 200 Chung-Pei Road, Chung Li District, Taoyuan City 32023, Taiwan; ttqm1992@gmail.com \\ 2 Department of Biomedical Engineering, Chung Yuan Christian University, 200 Chung-Pei Road, \\ Chung Li District, Taoyuan City 32023, Taiwan; noask518@gmail.com (K.-L.C.); \\ phoquochue@gmail.com (Q.-H.P.) \\ 3 Center for Biomedical Technology, Chung Yuan Christian University, 200 Chung-Pei Road, \\ Chung Li District, Taoyuan City 32023, Taiwan \\ 4 Department of Chemical Engineering, Industrial University of Ho Chi Minh City, 12 Nguyen Van Bao St., \\ Go Vap, Ho Chi Minh City 7000, Vietnam; nvc@iuh.edu.vn \\ 5 Graduate Institute of Health Industry Technology and Research Center for Industry of Human Ecology, \\ Chang Gung University of Science and Technology, No. 261, Wenhua 1st Road, Guishan District, \\ Taoyuan City 33303, Taiwan; Jennycheng@mail.cgust.edu.tw \\ 6 Department of Dermatology, School of Medicine, University of California, San Diego, CA 92121, USA; \\ chunming@ucsd.edu \\ * Correspondence: mfhsieh@cycu.edu.tw; Tel.: +886-3265-4550; Fax: +886-3265-4599
}

Academic Editor: Jianxun Ding

Received: 17 February 2016; Accepted: 22 August 2016; Published: 27 August 2016

\begin{abstract}
Acne is the over growth of the commensal bacteria Propionibacterium acnes (P. acnes) on human skin. Lauric acid (LA) has been investigated as an effective candidate to suppress the activity of $P$. acnes. Although LA is nearly insoluble in water, dimethyl sulfoxide (DMSO) has been reported to effectively solubilize LA. However, the toxicity of DMSO can limit the use of LA on the skin. In this study, LA-loaded poly( $\varepsilon$-caprolactone)-poly(ethylene glycol)-poly( $\varepsilon$-caprolactone) micelles (PCL-PEG-PCL) were developed to improve the bactericidal effect of free LA on P. acnes. The block copolymers mPEG-PCL and PCL-PEG-PCL with different molecular weights were synthesized and characterized using ${ }^{1} \mathrm{H}$ Nuclear Magnetic Resonance spectroscopy $\left({ }^{1} \mathrm{H}\right.$ NMR), Fourier-transform infrared spectroscopy (FT-IR), Gel Permeation Chromatography (GPC), and Differential Scanning Calorimetry (DSC). In the presence of LA, mPEG-PCL diblock copolymers did not self-assemble into nano-sized micelles. On the contrary, the average particle sizes of the PCL-PEG-PCL micelles ranged from 50-198 nm for blank micelles and 27-89 $\mathrm{nm}$ for LA-loaded micelles. The drug loading content increased as the molecular weight of PCL-PEG-PCL polymer increased. Additionally, the minimum inhibitory concentration (MIC) and the minimum bactericidal concentration (MBC) of free LA were 20 and $80 \mu \mathrm{g} / \mathrm{mL}$, respectively. The MICs and MBCs of the micelles decreased to 10 and $40 \mu \mathrm{g} / \mathrm{mL}$, respectively. This study demonstrated that the LA-loaded micelles are a potential treatment for acne.
\end{abstract}

Keywords: poly( $\varepsilon$-caprolactone)-poly(ethylene glycol)-poly( $\varepsilon$-caprolactone); lauric acid; micelles; Propionibacterium acnes; drug delivery system; nanoparticles

\section{Introduction}

Acne is the most common skin disease that appears usually in adolescence and adulthood. It is caused by the gram-positive bacterium Propionibacterium acnes (P. acnes) and mostly affects skin with 
many sebaceous glands or hair follicles. P. acnes induces monocytes to secrete pro-inflammatory cytokines, such as interleukin-1 $\beta$, interleukin- 8 , and interleukin-12, which then contribute to the inflammation [1-4]. The conventional antibiotic retinoid can ease acne symptoms for most patients, but contraindications in pregnant or lactating women limit their use $[3,5]$. Various antimicrobial agents and antibiotics have been developed to treat acne. Among those drugs, benzoyl peroxide (BPO) has been reported as one of the most important agents for reducing the acne vulgaris. However, BPO produces high erythema, scaling, and burning [3]. For that reason, attempts have been made to find new anti-acne agents with both excellent therapeutic efficacy and negligible adverse side effects [5].

Short-chain fatty acids (SCFAs) have been known to exhibit self-antimicrobial activity to prevent microbial colonization. Previous studies of various SCFAs have demonstrated their antibacterial efficacy [2,6]. For example, oleic acid was reported to inhibit the growth of Staphylococcus aureus in a mouse model, and linoleic acid overcame antibiotic resistance developed by various clinically isolated strains of Helicobacter pylori [6]. In 2009, lauric acid (LA) was reported as a bactericidal agent for acne less harmful than benzoyl peroxide (BPO) [2,3,7]. However, the use of LA is limited due to its low solubility in water. Although dimethyl sulfoxide (DMSO) has been reported to improve the solubility of LA, the cytotoxicity of DMSO can limit its usefulness in the treatment of acne [3].

Recent studies of drug-loaded polymeric micelles showed enhanced characteristics of these materials, such as antibacterial efficiency, stability, drug solubility, and selective targeting [8,9]. Poly( $\varepsilon$-caprolactone) (PCL) has been studied as an ideal material for drug delivery because of its adjustable degradation time $[8,10,11]$. On the contrary, poly(ethylene glycol) (PEG) is a water-soluble, non-toxic molecule that has no antigenicity immunogenicity and can thus co-polymerize with $\varepsilon$-caprolactone $(\varepsilon-C L)$ to take advantage of its improved bioavailability and biodegradation as well as mild toxicity [8,10-12].

Amphiphilic block copolymers have received particular interest as drug delivery systems because of their ability to self-assemble into nano-sized micelles. Various structures of block copolymers have been used to encapsulate hydrophobic drugs, such as $\mathrm{AB}$ diblock copolymers where the A block of the hydrophobic segment is at the core, and the B block of the hydrophilic segment is distributed on the outer surface of the micelles [13]. However, most drugs encapsulated in this type of polymeric micelle are anticancer drugs such as doxorubicin. The challenges to incorporate fatty acids or lipids arise from the incompatibility of the hydrocarbon chain to the PCL segment in the core of the micelles. Recently, Hallouard et al. reported iodinated oil-loaded PCL/PCL-mPEG formulation for the application of computerized tomography contrast agent [14]. To prepare stable formulations, the PCL-mPEG diblock copolymer was mixed with PCL in their study. As such, the hydrophobic phase in the formulation plays a pivotal role in stabilizing lipid drug encapsulation in the nanoparticles. ABA triblock copolymers, such as PCL-PEG-PCL, are variants of the diblock copolymers where the composition of the hydrophobic phase is increased in the formulation compared with that of a drug carrier using the $\mathrm{AB}$ diblock copolymer.

In this study, we synthesized PCL-PEG-PCL copolymers as drug carriers of LA. For comparison, mPEG-PCL diblock copolymers were also studied. In aqueous medium, this copolymer can form nano-sized micelles. The physical properties of the blank and LA-loaded micelles were characterized, including particle size and zeta potential. The minimum inhibitory concentration (MIC) and the minimum bactericidal concentration $(\mathrm{MBC})$ of free LA and LA-loaded micelles on P. acnes were determined.

\section{Experimental Section}

\subsection{Materials}

Poly(ethylene glycol) (PEG, $\left.M_{n}=4000\right)$ was purchased from Showa (Tokyo, Japan); $\varepsilon$-caprolactone ( $\varepsilon-C L)$, polymerization catalyst $\mathrm{Sn}(\mathrm{Oct})_{2}$, dimethyl sulfoxide (DMSO), 1,6-diphenyl-1,3,5-hexatriene (DPH), 3-(4,5-dimethylthiazol-2-yl)-2,5-diphenyltetrazolium bromide (MTT), Noble agar, phosphotungstic 
acid, potassium bromide ( $\mathrm{KBr})$, potassium phosphate monobasic, sodium chloride, and sodium phosphate were all purchased from Sigma-Aldrich Chem. Inc. (St. Louis, MO, USA). Acetone, acetonitrile $(\mathrm{ACN})$, D-chloroform $\left(\mathrm{CDCl}_{3}\right)$, dichloromethane, ethyl ether, ethanol, hexane, and tetrahydrofuran were provided by ECHO Chemicals (Miaoli, Taiwan).

\subsection{Synthesis of PCL-PEG-PCL Copolymers}

The PCL-PEG-PCL copolymer (named as PCEC) was synthesized by a ring-opening polymerization reaction as previously described with some modifications [11]. The molecular weights of the PCEC copolymers were designed for $8000,14,000$, and $24,000 \mathrm{Da}$, corresponding to $\mathrm{PC}_{20} \mathrm{E}_{40} \mathrm{C}_{20}$, $\mathrm{PC}_{50} \mathrm{E}_{40} \mathrm{C}_{50}$, and $\mathrm{PC}_{100} \mathrm{E}_{40} \mathrm{C}_{100}$, respectively. The ratios of the molecular weights of the hydrophilic block to the hydrophobic block were 1:1, 1:2.5, and 1:5, respectively. Specifically, to synthesize $\mathrm{PC}_{20} \mathrm{E}_{40} \mathrm{C}_{20}$, a three-necked round bottom flask was purged by a continuous flow of nitrogen gas and heated at $90{ }^{\circ} \mathrm{C}$. Then, $10 \mathrm{~g}$ of PEG $\left(M_{\mathrm{w}}=4000\right)$ and $0.146 \mathrm{~mL}$ of catalyst $\mathrm{Sn}(\mathrm{Oct})_{2}(1 \mathrm{molar} \%$ of $\varepsilon$-CL) were introduced into the flask under mechanical stirring for $30 \mathrm{~min}$. After the temperature was increased to $130^{\circ} \mathrm{C}, 10 \mathrm{~g}$ of $\varepsilon$-CL was added to the flask for a 12-h reaction [11,15]. The resulting product was dissolved in dichloromethane and precipitated in diethyl ether:n-hexane at a volumetric ratio of 7:3. This step was repeated several times to purify the product. Finally, the product was filtered and dried under a vacuum for $24 \mathrm{~h}$.

\subsection{Characterization of the PCL-PEG-PCL Copolymers}

After synthesis of the PCEC triblock copolymers, the resulting samples were characterized by different physicochemical methods. The PCEC vibrational spectra were measured using a Fourier-transform infrared (FT-IR) spectrometer (model 410, JASCO, Tokyo, Japan) in the range of 4000 to $400 \mathrm{~cm}^{-1}$. The samples were compressed with $\mathrm{KBr}$ for spectral measurements. The copolymer chemical structure was determined by ${ }^{1} \mathrm{H}$ Nuclear Magnetic Resonance spectroscopy $\left({ }^{1} \mathrm{H}\right.$ NMR) using $\mathrm{CDCl}_{3}$ as a solvent operating at $500 \mathrm{MHz}$ (Bruker, Billerica, MA, USA). The molecular weight of the copolymers was estimated by calculating the integrated peak area of the MPEG and PCL segments from the ${ }^{1} \mathrm{H}$ NMR spectra. In addition, Gel Permeation Chromatography (GPCmax, Viscotek, Houston, TX, USA) was used to measure the molecular weights and the distribution of the PCEC triblock copolymers using THF as the mobile phase. Polystyrene (PS) standards were used to calibrate the number-average and weight-average molecular weights. The thermal properties (melting/crystallization) of the copolymers were investigated by Differential Scanning Calorimetry (Jade DSC, PerkinElmer, Waltham, MA, USA) with a range of heating temperatures from 20 to $100^{\circ} \mathrm{C}$ under a nitrogen atmosphere at a heating and cooling rate of $5{ }^{\circ} \mathrm{C} / \mathrm{min}$.

\subsection{Preparation of Blank or LA-Loaded PCL-PEG-PCL Nano-Sized Micelles}

Micelle preparation was carried out by following the thin film hydration method as reported elsewhere [16]. Briefly, various amounts of PCEC and LA were co-dissolved in ACN at different ratios as shown in Table 1. The resulting solutions were rigorously mixed by a vortex. Afterwards, ACN was removed by a rotary evaporator at $60^{\circ} \mathrm{C}$, and $2 \mathrm{~mL}$ of deionized water kept at $80^{\circ} \mathrm{C}$ was then added rapidly to the dried samples in an ultrasonic bath for $10 \mathrm{~min}$. After stirring for $3 \mathrm{~h}$ at room temperature, the micellar solution was centrifuged $(2500 \mathrm{~g}, 10 \mathrm{~min})$ and filtered through a $0.45-\mu \mathrm{m}$ filter. Particle size and zeta potential of the micelles were measured using a zeta potential analyzer (90Plus, Brookhaven Instruments Corporation, Holtsville, NY, USA). The morphology of the prepared micelles was observed on a Transmission electron microscope (TEM) (JEM2000FXII, JOEL, Tokyo, Japan), and $0.5 \mathrm{mg} / \mathrm{mL}$ micellar solutions were spotted on a copper grid. The samples were negatively stained with phosphotungstic acid $(0.1 \mathrm{wt} \%)$ and dried at room temperature. 
Table 1. Preparation of blank nano-sized micelles and lauric acid (LA)-loaded micelles with different polymer to LA ratios. The copolymer name subscript indicates $1 / 100$ of the designed molecular weights of each segment.

\begin{tabular}{ccc}
\hline PCEC copolymer & PCEC:LA (mg:mg) & Abbreviation \\
\hline $\mathrm{PC}_{20} \mathrm{E}_{40} \mathrm{C}_{20}$ & $10: 0$ & $\mathrm{MC}_{20}$ \\
& $10: 2$ & $\mathrm{MC}_{20} \mathrm{LA}$ \\
$\mathrm{PC}_{50} \mathrm{E}_{40} \mathrm{C}_{50}$ & $10: 0$ & $\mathrm{MC}_{50}$ \\
& $10: 2$ & $\mathrm{MC}_{50} \mathrm{LA}$ \\
$\mathrm{PC}_{100} \mathrm{E}_{40} \mathrm{C}_{100}$ & $10: 0$ & $\mathrm{MC}_{100}$ \\
& $10: 2$ & $\mathrm{MC}_{100} \mathrm{LA}$ \\
\hline
\end{tabular}

\subsection{Critical Micelle Concentration (CMC)}

The CMC of the copolymer was measured by the pyrene 1:3 method using DPH as a fluorescent probe $[3,17]$. The polymeric micelles were prepared to obtain a range of concentrations between $1.2 \times 10^{-3}$ and $2 \mathrm{mg} / \mathrm{mL}$. Aliquots $(2 \mathrm{~mL})$ of the polymeric micelles were added to $20 \mu \mathrm{L}$ of $\mathrm{DPH}$ $(0.4 \mathrm{mM}$ in $\mathrm{MeOH})$ to give a $4 \times 10^{-6} \mathrm{M} \mathrm{DPH} /$ copolymer solution. The resultant solution was incubated in the dark for $5 \mathrm{~h}$. The intensities $I_{1}$ and $I_{3}$ were measured at wavelengths corresponding to the first and third vibronic bands at 373 and $384 \mathrm{~nm}$ [17]. The CMC of the copolymer was determined based on plots of $I_{1} / I_{3}$ ratio and concentrations.

\subsection{Loading Content of $L A$ in the Micelles}

To determine the loading content of LA in the micelles, the samples were first dried by rotary evaporation following by dissolving in methanol and chemically deriving with naphthacyl ester $[3,18]$. Briefly, $100 \mathrm{mg}$ of $\mathrm{KHCO}_{3}$ was added into $1 \mathrm{~mL}$ of as-prepared micelles and dried overnight. Subsequently, the samples were mixed with a solution of $20 \mathrm{mM}$ 2-bromo-2'-acetonaphthone and $4.54 \mathrm{mM}$ 18-crown- 6 and then kept at $80{ }^{\circ} \mathrm{C}$ for $30 \mathrm{~min}$ using a Thermomixer (Eppendorf 5810, Westbury, NY, USA). The resulting solutions were measured by reversed-phase high performance liquid chromatography (HPLC) (Alliance 2695 separation module, Waters, Milford, MA, USA) using a Nova-Pak C18 column $(4 \mu \mathrm{m}, 4.6 \mathrm{~mm} \times 250 \mathrm{~mm}$, Waters) and a guard column (Nova-Pak C18; $4 \mu \mathrm{m}, 3.9 \mathrm{~mm} \times 20 \mathrm{~mm}$, Waters). The column temperature was maintained at $30^{\circ} \mathrm{C}$ with a solvent gradient of methanol/acetonitrile/water ranging from 80:10:10 $(v / v / v)$ that was increased linearly to 90:10:0 $(v / v / v)$. Derived LA was detected by UV/VIS absorbance at a wavelength of $254 \mathrm{~nm}$ at $20^{\circ} \mathrm{C}$. The concentration of LA was calculated according to the following equations that had been produced from the calibration curve of free LA.

$$
\text { Drug loading content }(\text { DLC })=\frac{\text { Amount of LA in micelles }}{\text { Amount of polymer }+ \text { LA }} \times 100 \%
$$

\subsection{Preparation of Bacteria for Antibacterial Testing}

In this study, Propionibacterium acnes (P. acnes) (BCRC 10723) was purchased from the Bioresource Collection and Research Center (Hsinchu, Taiwan). P. acnes was cultured in Reinforced Clostridial Medium (RCM) (OXOID, Hampshire, UK) under anaerobic conditions using Gas-Pak (AnaeroPack-Anaero, Mitsubishi Gas Chemical Co., Tokyo, Japan) with rotary shaking at $37^{\circ} \mathrm{C}$. Consequently, the culture was maintained until it reached an $\mathrm{OD}_{600}$ value of 0.7 . The bacteria were harvested by centrifugation ( $5000 \mathrm{~g}$ for $10 \mathrm{~min}$ ) and then washed with sterile PBS and suspended in an appropriate amount of PBS for further experiments.

\subsection{Minimum Inhibitory Concentration of the Micelles}

MIC is the lowest concentration of an antimicrobial agent necessary to prevent bacterial growth. In our study, the concentration of free LA and micelles that inhibited $50 \%$ of P. acnes $\left(\mathrm{MIC}_{50}\right)$ was 
determined using the two-fold serial dilution method $[19,20]$. The cultured bacteria were measured by spectrophotometer at an absorbance wavelength of $600 \mathrm{~nm}$ and a concentration of $2 \times 10^{6}(\mathrm{CFU} / \mathrm{mL})$. In a 96-well plate, $100 \mu \mathrm{L}$ of the original bacterial suspension was pipetted into the first well. Two-fold serial dilutions were made from the 2nd to 11th wells with $50 \mu \mathrm{L}$ of PBS, and thus the concentration of bacteria was $10^{6} \mathrm{CFU} / \mathrm{mL}$, which was then incubated with LA or LA-loaded micelles $(0-100 \mu \mathrm{g} / \mathrm{mL})$ in PBS under aerobic conditions for $24 \mathrm{~h}$. The control received only 5\% DMSO. Later on, the absorbance at $600 \mathrm{~nm}$ was measured to estimate bacterial growth.

\subsection{The Minimum Bactericidal Concentration of Micelles}

MBC is the lowest concentration of an antibacterial agent that reduces the viability of the initial bacterial inoculum by $\geq 99.9 \%$. It can be determined by the following two steps: incubation in RCM broth (19 $\mathrm{g}$ RCM in $500 \mathrm{~mL}$ double-distilled water) and then sub-culture on RCM agar plates (19 $\mathrm{g}$ of RCM and $7.5 \mathrm{~g}$ of agar in $500 \mathrm{~mL}$ of DD water). To determine the MBC of free LA or LA-loaded micelles against $P$. acnes, $1 \times 10^{7} \mathrm{CFU} / \mathrm{mL}$ P. acnes was incubated with various concentrations of LA or LA-loaded micelles $(0-100 \mu \mathrm{g} / \mathrm{mL})$ in PBS at $37^{\circ} \mathrm{C}$ for $5 \mathrm{~h}$ under anaerobic conditions, and $5 \%$ DMSO in PBS was used as a control. The mixture then was diluted from $10^{-1}$ to $10^{-6}$ times in PBS. Five microliters of the diluted solutions were spotted on RCM agar plates, which were then incubated at $37^{\circ} \mathrm{C}$ for $96 \mathrm{~h}$. The number of colony forming units (CFUs) was calculated using the following equation $[19,21]$ :

$$
\mathrm{CFU}=\frac{\text { Number of colonies counted }}{\text { Amount plates }(\text { in } \mathrm{mL}) \times \text { dilution }}
$$

\section{Results and Discussion}

\subsection{Characterization of PCL-PEG-PCL Copolymers (PCECs)}

PCECs were synthesized with three different molecular weights. The PEG, which functioned as the central segment, had a molecular weight of $4000 \mathrm{Da}$, and the theoretical molecular weight of PCL segments at both ends, as displayed in Table 2, were 4000, 10,000, and 20,000 Da. The FT-IR spectra of the PCECs are shown in Figure 1. The results demonstrated that the peak of C-H stretching appeared at 2947 and $2877 \mathrm{~cm}^{-1}$, which proved the existence of PCL segments in the copolymer. A C $=\mathrm{O}$ stretching band was observed at $1728 \mathrm{~cm}^{-1}$, which can be attributed to the PCL segment, and another peak appeared at $1103 \mathrm{~cm}^{-1}$ for $\mathrm{C}-\mathrm{O}-\mathrm{C}$ stretching vibration of the repeated $-\mathrm{OCH}_{2} \mathrm{CH}_{2}$ units of PEG [22-25]. In addition, those peaks were also found in the spectra of $\mathrm{PC}_{20} \mathrm{E}_{40} \mathrm{C}_{20}$ and $\mathrm{PC}_{50} \mathrm{E}_{40} \mathrm{C}_{50}$. In Figure 1, when the molecular weight of the PCL segment was increased, the intensity of the peak at $1103 \mathrm{~cm}^{-1}$ was slightly decreased with respect to $1728 \mathrm{~cm}^{-1}$, which was the $\mathrm{C}=\mathrm{O}$ of PCL. That is because the more abundant amount of PCL in PCECs led to pronounced areas of $\mathrm{C}=\mathrm{O}$ stretching peak.

According to the ${ }^{1} \mathrm{HNMR}$ spectra of PCECs, the chemical structure of PCECs was determined (Figure S1). Protons of the PEG segment were investigated at $\delta=3.6 \mathrm{ppm}$, whereas the chemical shifts of protons in the PCL segment were $\delta=2.3,1.6,1.3$, and $4.0 \mathrm{ppm}$ [26]. To estimate the molecular weights of PCECs, the areas under the peak in ${ }^{1} \mathrm{H}$ NMR spectra were used. Based on the known molecular weights of PEG (4000 Da), the peak areas of each hydrogen on the polymer were obtained. After that, the molecular weights of the polymerized PCL segments were calculated. In addition to the molecular weights estimated by ${ }^{1} \mathrm{H}$ NMR, the molecular weights measured by GPC are also summarized in Table 2 . According to the molecular weights estimated by ${ }^{1} \mathrm{HNMR}$, the molecular weights of $\mathrm{PC}_{20} \mathrm{E}_{40} \mathrm{C}_{20}, \mathrm{PC}_{50} \mathrm{E}_{40} \mathrm{C}_{50}$, and $\mathrm{PC}_{100} \mathrm{E}_{40} \mathrm{C}_{100}$ were close to the theoretical values. In GPC analysis, the number of average molecular weight $\left(M_{\mathrm{n}}\right)$ and average molecular weight $\left(M_{\mathrm{W}}\right)$ deviated from the theoretical values because the conventional standard (polystyrene) was used. However, the polydispersity indexes of the PCECs were 1.17, 1.29, and 1.33. This indicates that the molecular weights of PCECs were narrowly distributed, especially for $\mathrm{PC}_{20} \mathrm{E}_{40} \mathrm{C}_{20}$. 


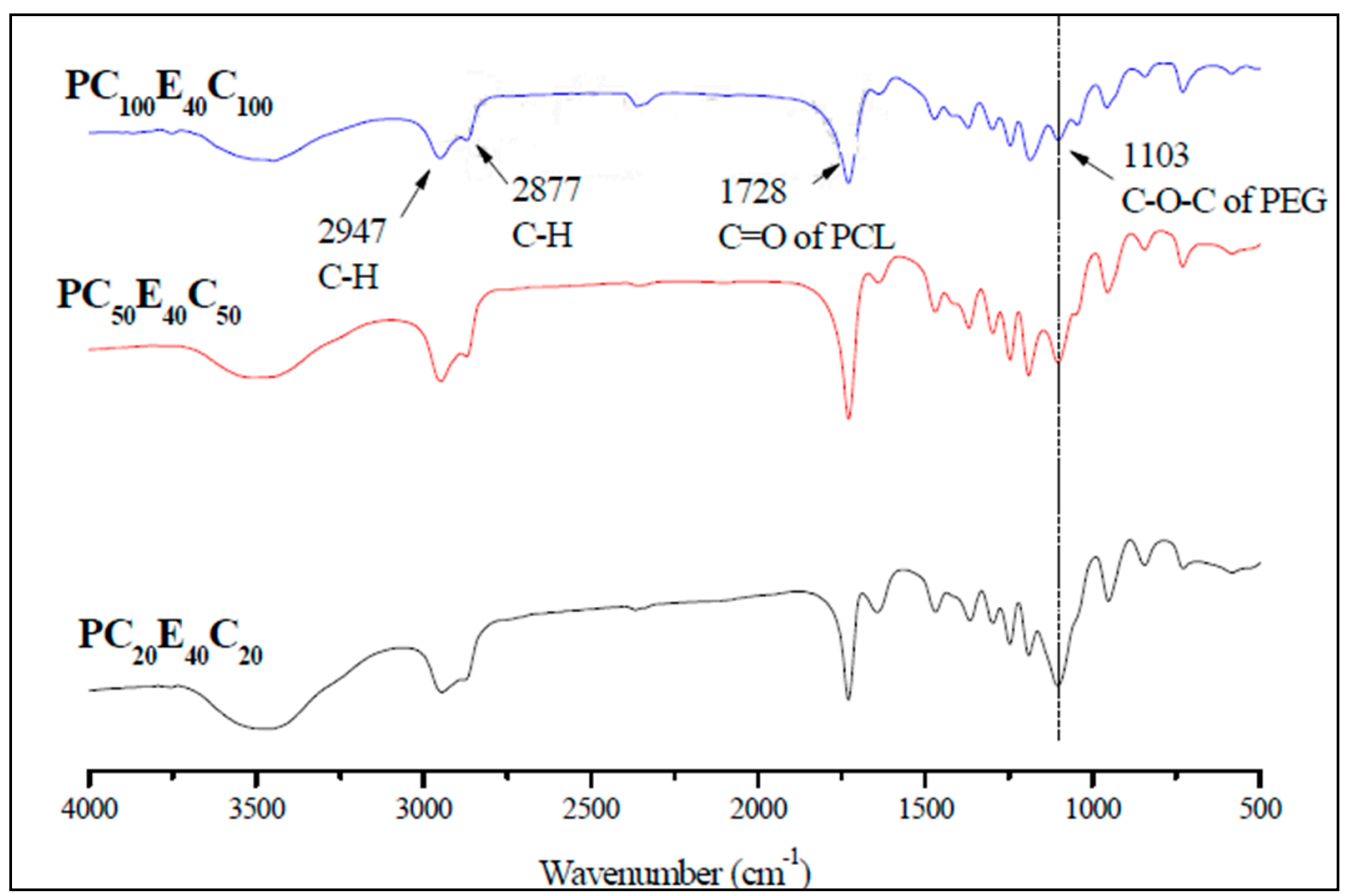

Figure 1. Fourier-transform infrared spectra of three PCL-PEG-PCL copolymers. The polymers were pelleted with $\mathrm{KBr}$ for transmission measurement. The $Y$-axis indicates the transmittance $(\%)$.

Table 2. Molecular weights of PCECs and critical micelle concentration (CMC). The first column displays the theoretical molecular weights of the PCECs. All molecular weights are expressed asg $/ \mathrm{mol}$.

\begin{tabular}{ccccccc}
\hline & & $\overline{\boldsymbol{M}}_{\mathbf{N M R}}{ }^{\text {a }}$ & $\overline{\boldsymbol{M}}_{\mathbf{n}}$ b & $\overline{\boldsymbol{M}}_{\mathbf{w}}{ }_{\mathrm{b}}$ & Polydispersity index & CMC (wt \%) \\
\hline $\mathrm{PC}_{20} \mathrm{E}_{40} \mathrm{C}_{20}$ & 8000 & 8127 & 8320 & 9727 & 1.17 & $5.43 \times 10^{-3}$ \\
$\mathrm{PC}_{50} \mathrm{E}_{40} \mathrm{C}_{50}$ & 14,000 & 13,698 & 10,831 & 13,999 & 1.29 & $4.17 \times 10^{-3}$ \\
$\mathrm{PC}_{100} \mathrm{E}_{40} \mathrm{C}_{100}$ & 24,000 & 22,571 & 14,154 & 18,838 & 1.33 & $2.16 \times 10^{-3}$ \\
\hline
\end{tabular}

a: $\bar{M}_{\text {MNR }}$ obtained from the ${ }^{1} \mathrm{H}$ Nuclear Magnetic Resonance spectroscopy $\left({ }^{1} \mathrm{H}\right.$ NMR $)$ analysis; ${ }^{\mathrm{b}}: \bar{M}_{\mathrm{n}}$ and $\bar{M}_{\mathrm{w}}$ obtained from Gel Permeation Chromatography (GPC) analysis.

Differential Scanning Calorimetry (DSC) was used to characterize the thermal properties of the synthesized copolymers. The thermograms for the second heating/cooling curves were recorded and are displayed in Figure S2. For $\mathrm{PC}_{20} \mathrm{E}_{40} \mathrm{C}_{20}$ and $\mathrm{PC}_{50} \mathrm{E}_{40} \mathrm{C}_{50}$, the thermograms showed double peaks, indicating two melting temperatures $\left(T_{\mathrm{m}}\right)$ assigned for PEG and PCL, respectively. The higher melting temperatures of $\mathrm{PC}_{20} \mathrm{E}_{40} \mathrm{C}_{20}$ and $\mathrm{PC}_{50} \mathrm{E}_{40} \mathrm{C}_{50}$ were determined to be 49.41 and $51.39{ }^{\circ} \mathrm{C}$, respectively, which corresponded to the melting point of the PCL segment in the crystal phase. Although the PCL-PEG-PCL was a copolymer, the segments PEG and PCL segments remained phase separated. Therefore, bimodal melting points were observed in $\mathrm{PC}_{20} \mathrm{E}_{40} \mathrm{C}_{20}$ and $\mathrm{PC}_{50} \mathrm{E}_{40} \mathrm{C}_{50}$ [27]. The $T_{\mathrm{m}}$ of PEG was relatively decreased along with the increase in the molecular weight of the PCECs. By contrast, there was only a single melting point at $54.22{ }^{\circ} \mathrm{C}$ for $\mathrm{PC}_{100} \mathrm{E}_{40} \mathrm{C}_{100}$, indicating the cooperative crystallization of PEG and PCL segments and/or the strong crystallization of the PCL segment. As a result, the PEG peak disappeared. The increased melting point is alternative evidence to demonstrate the increased molecular weight of the PCECs.

\subsection{Characterization of PCL-PEG-PCL Micelles}

\subsubsection{The Critical Micelle Concentration of PCL-PEG-PCL}

The CMC is used to estimate the lowest formation concentration of the micelles in water. The CMC is a particularly important parameter for micelle-based drug delivery systems to avoid burst release 
upon injection into the bloodstream. When the concentration of the amphiphilic block copolymers is below the CMC, it becomes thermodynamically unstable [28]. Determination of the CMCs for the PCECs was carried out by serial dilution of micellar solutions. Then, absorption of fluorescent probe (DPH) included in the cores of the micelles was recorded. We adopted the pyrene 1:3 ratio method to determine the CMC. The values of the micelles were determined based on the relationship of the intensity ratio of $I_{1} / I_{3}$ of pyrene included in the micelles and the concentrations. As shown in Figure 2, the CMC value was determined at the center point of the sigmoid. The CMC values of $\mathrm{PC}_{20} \mathrm{E}_{40} \mathrm{C}_{20}, \mathrm{PC}_{50} \mathrm{E}_{40} \mathrm{C}_{50}$, and $\mathrm{PC}_{100} \mathrm{E}_{40} \mathrm{C}_{100}$ (summarized in Table 2) were $5.43 \times 10^{-3}, 4.17 \times 10^{-3}$, and $2.16 \times 10^{-3} \mathrm{wt} \%$, respectively. Apparently, the CMC values were reduced when the molecular weight (chain length) of the hydrophobic segment of PCL was increased from 2000 to 10000 Da [29]. This is because when the chain length of PCL is increased, the hydrophobic segments of PCL can pack more efficiently, and the hydrophobic interactions within the core of micelles are increased. Hence, the PCEC copolymers can more easily self-assemble in aqueous solution to form micelles, resulting in increased micelle stability in aqueous solutions at relatively lower concentrations [30]. Figure S3 displays the $\mathrm{CMC}$ values of diblock copolymers as $16.4 \times 10^{-3}, 8.91 \times 10^{-3}$, and $4.47 \times 10^{-3} \mathrm{wt} \%$ for $\mathrm{PC}_{75}, \mathrm{PC}_{100}$, and $\mathrm{PC}_{150}$, respectively. Figures S4-S6 display the physicochemical characterizations of diblock copolymers and Table S1 shows the summary of the results. Obviously, the increase in the hydrophobic segment (PCL in this study) leads to lower CMC values. Not only do the drug delivery systems for parental injection benefit from low CMC values but also those delivered through the skin can remain stable even after multiple doses [31]. Therefore, the results demonstrated that the stability of the micelle formed by triblock PCECs is more stable than that of diblock PCs.

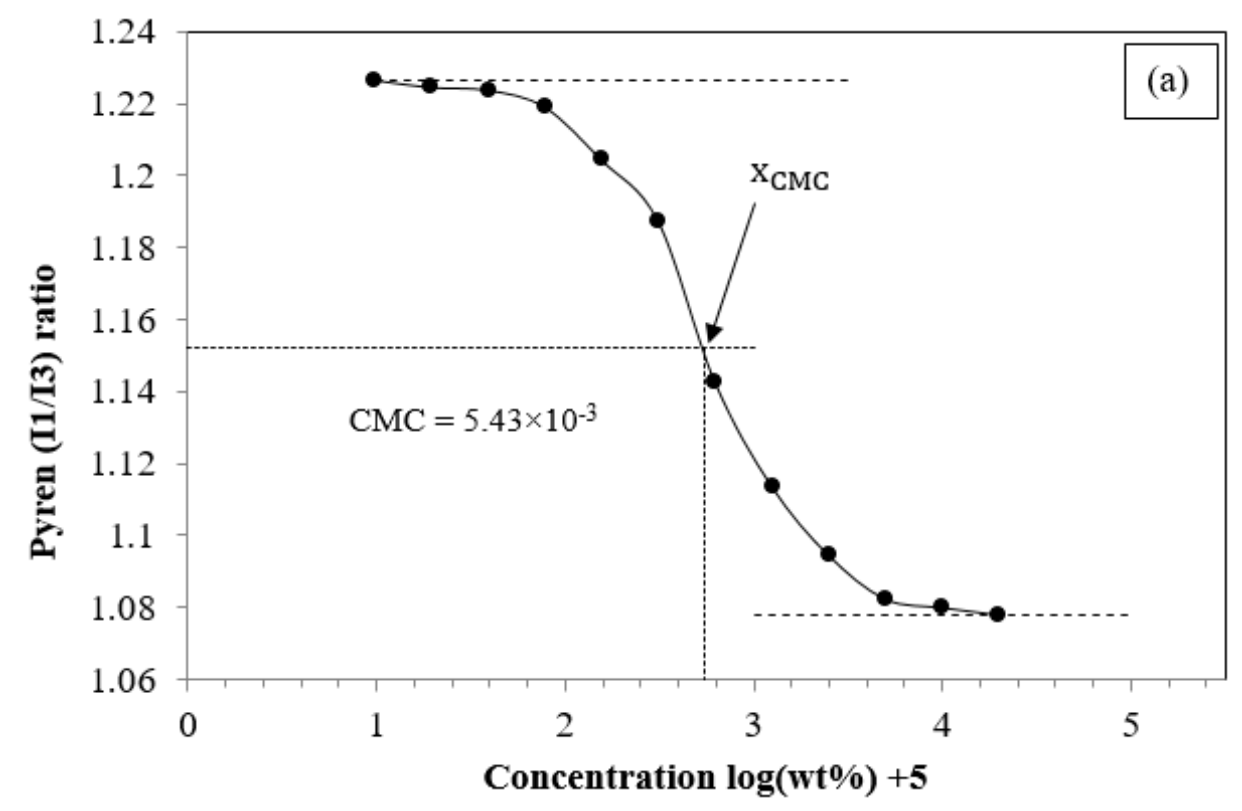

Figure 2. Cont. 

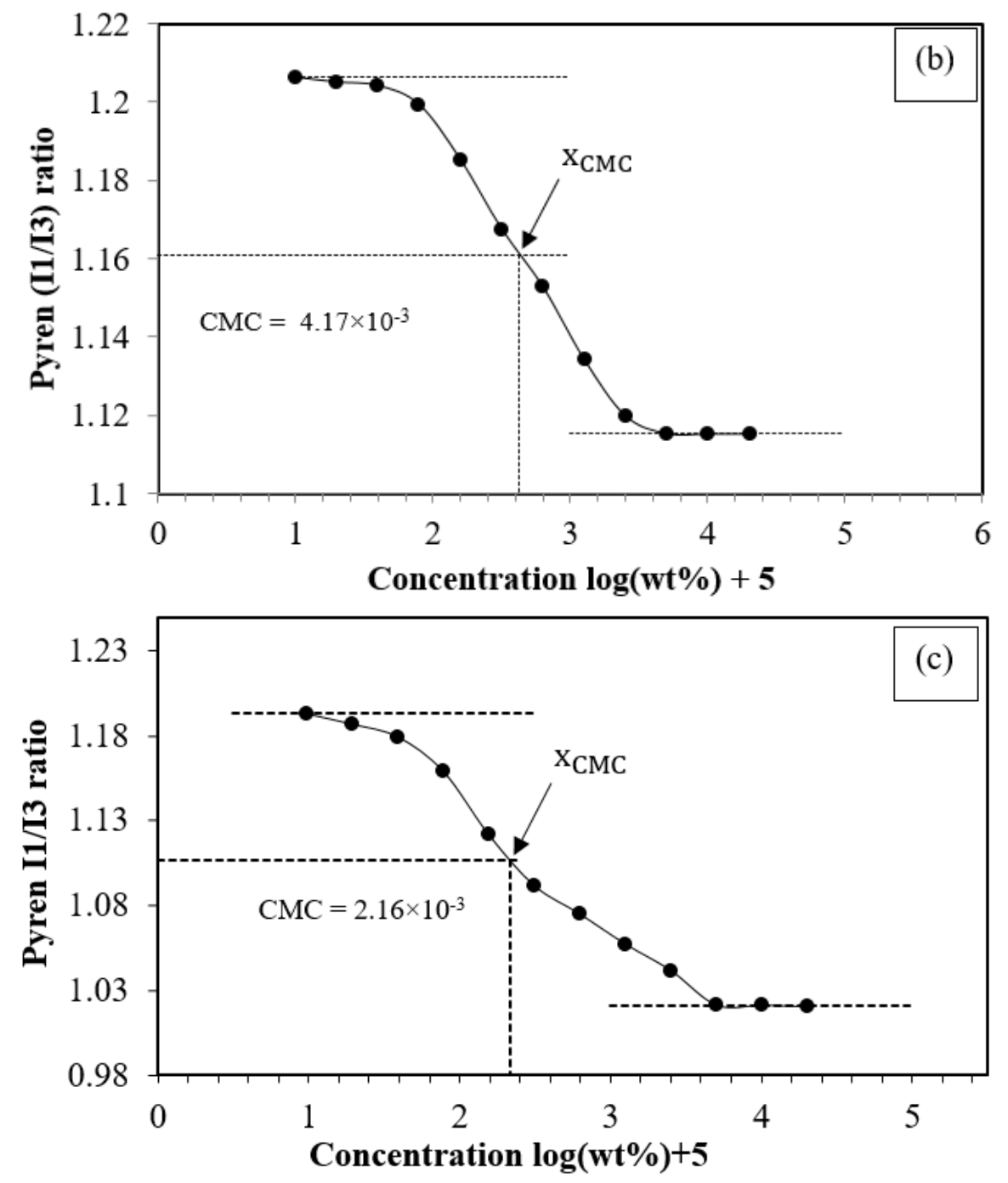

Figure 2. Measurement of critical micelle concentration (CMC) values for (a) $\mathrm{PC}_{20} \mathrm{E}_{40} \mathrm{C}_{20}$; (b) $\mathrm{PC}_{50} \mathrm{E}_{40} \mathrm{C}_{50}$; (c) $\mathrm{PC}_{100} \mathrm{E}_{40} \mathrm{C}_{100}$.

As described in the experimental section, the micelle preparation method was similar to that of liposomes. During the hydration, the PCECs were added into hot water $\left(80{ }^{\circ} \mathrm{C}\right)$, which was high enough to soften the polymers and allow them to easily self-assemble in aqueous solutions. As observed, the solution turned from transparent to turbid (shown in Figure 3) when hot water was added to the dried PCEC film.

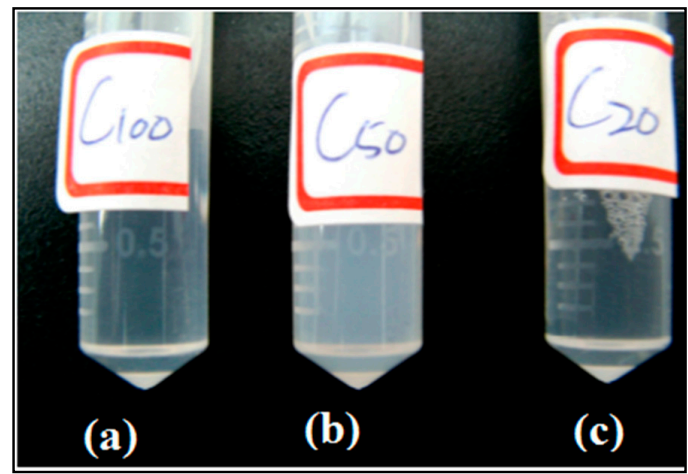

Figure 3. The results of hydration of the micelle aqueous solutions. (a) $\mathrm{MC}_{100}$; (b) $\mathrm{MC}_{50}$; (c) $\mathrm{MC}_{20}$. 


\subsubsection{Particle Size and Surface Charges of the Micelles}

The particle size and distribution of the MC micelles are displayed in Table 3. The average particle sizes were 50, 78, and $198 \mathrm{~nm}$ for $\mathrm{MC}_{20}, \mathrm{MC}_{50}$, and $\mathrm{MC}_{100}$, respectively. When the ratio of PCEC to $\mathrm{LA}$ was 10:2, the particle sizes of $\mathrm{MC}_{20} \mathrm{LA}, \mathrm{MC}_{50} \mathrm{LA}$, and $\mathrm{MC}_{100} \mathrm{LA}$ were reduced to 27,68 , and $89 \mathrm{~nm}$, respectively. For blank micelles, the greater the chain length of the PCL segment, the larger was the average particle size of the micelles. When LA was loaded onto the micelles, the average particle size of the micelles decreased. Previous studies on poly(lactic-co-glycolic acid) (PLGA) micelles loading caprylic acid (C8) [32] showed that caprylic acid could decrease the particle size of the micelles. Similar reports have indicated that the core of the micelle, in which the hydrophobic segment can accommodate a hydrophobic reagent, leads to a reduction in the particle size of the micelles [33].

Additionally, a similar result for particle size was also found in blank micelles of diblock copolymers (Figure S7c). The average diameters of the blank micelles for $\mathrm{PC}_{75}, \mathrm{PC}_{100}$, and $\mathrm{PC}_{150}$ were 51, 61, and $88 \mathrm{~nm}$, respectively. This demonstrated that particle sizes less than $100 \mathrm{~nm}$ can be easily fabricated using both the diblock and triblock copolymers synthesized in this study. However, we observed that LA-loaded micelles of diblock copolymers (PCs) have particle sizes over the nanoscale, e.g., all of them were micron-sized (Figure S7d). This dramatic change can also be observed under microscopy. Figure S7b indicates the morphology of PC particles along with oil droplets. Apparently, diblock copolymers of mPEG-PCL are difficult to self-assemble into stable micelles in the presence of LA, and, as a result, the suspensions were found (Figure S7a). As mentioned in the Introduction, the efficient loading of fatty acids or lipids requires higher loading of hydrophobic components of drug carriers, such as the addition of a single PCL into the formulation to form oil-loaded micelles $[13,34,35]$.

Table 3. The particle sizes and distribution of the micelles. PDI stands for polydispersity index.

\begin{tabular}{ccccc}
\hline Micelle & PCEC:LA $(\mathbf{m g} / \mathbf{m g})$ & Average particle size $(\mathbf{n m})$ & PDI & Zeta potential $(\mathbf{m V})$ \\
\hline C $_{20}$ & $10: 0$ & 50 & 0.27 & -2.98 \\
$\mathrm{MC}_{20}$ LA & $10: 2$ & 27 & 0.33 & -7.23 \\
$\mathrm{MC}_{50}$ & $10: 0$ & 78 & 0.24 & -5.90 \\
$\mathrm{MC}_{50}$ LA & $10: 2$ & 68 & 0.21 & -16.57 \\
$\mathrm{MC}_{100}$ & $10: 0$ & 198 & 0.14 & -9.88 \\
$\mathrm{MC}_{100}$ LA & $10: 2$ & 89 & 0.21 & -18.38 \\
\hline
\end{tabular}

The surface charge of a micelle is one of the important factors in identifying the interactions of a micelle with bacteria, and it is typically measured as zeta-potential. Loading of a compound on to the micelle can cause the changes in the electrical potential profile on the micelle surface [3]. The zeta potentials of $\mathrm{MC}_{20}, \mathrm{MC}_{50}$, and $\mathrm{MC}_{100}$ were $-2.98,-5.90$, and $-9.88 \mathrm{mV}$, respectively and those of the $\mathrm{MC}_{20} \mathrm{LA}, \mathrm{MC}_{50} \mathrm{LA}$, and $\mathrm{MC}_{100} \mathrm{LA}$ micelles were $-7.23,-16.57$, and $-18.38 \mathrm{mV}$, respectively (Figure 4). These results demonstrated that the micelles with and without LA were negatively charged and that LA can decrease the zeta-potential of the micelles. Because the $\mathrm{p} K_{\mathrm{a}}$ of free fatty acids is approximately 5 , in near physiological medium, the carboxyl group of the free fatty acids (LA in this study) will thus deprotonate and distribute to the negatively charged of micelles at $\mathrm{pH}=7.4[3,19]$. Notably, LA, which is amphiphilic in its chemical structure, is not only solubilized in the core of micelles but also located at the interface of the core-shell of the micelle. Therefore, the presence of LA results in a reduction of the zeta potential [36]. 




Figure 4. The average particle size and zeta potential of the micelles.

\subsubsection{Transmission Electron Microscopy of the Micelles}

Due to the nature of amphiphilic molecules, PCEC copolymers form a core-shell structure. TEM images of the blank micelles and LA-loaded micelles are shown in Figure 5. For blank micelles, the morphology of the dried micelles was spherical with diameters of 25-40 nm for $\mathrm{MC}_{20}$ (Figure $5 \mathrm{a}$ ), $30-40 \mathrm{~nm}$ for $\mathrm{MC}_{50}$ (Figure 5b), and $40-50 \mathrm{~nm}$ for $\mathrm{MC}_{100}$ (Figure 5c). Because LA is a type of surfactant, we speculated that LA can form micelles (nanoparticles) under the same preparation protocol when no PCECs were added. However, there were no particles observed in the TEM images (images not shown). The diameter of the micelles was reduced to 20-30 nm for $\mathrm{MC}_{50} \mathrm{LA}$ (Figure 5e) and 20-40 nm for $\mathrm{MC}_{100} \mathrm{LA}$ (Figure 5f). The decreased micellar diameter after loading LA was appropriate with previous hypotheses [30], which demonstrated that reagents (LA in this study) could be incorporated into micelles.

Regarding the morphology of the dried micelles observed under TEM, there were small and non-spherical particles in the micelles after loading the LA, particularly in the $\mathrm{MC}_{20} \mathrm{LA}$ micelles (Figure 5d). When LA was loaded into the micelles, it interacted with the PCL segment through hydrophobic interactions, and the polar head group (carboxylic acid) may have been inserted into the shell layer. As a result, the nanoparticles can lose their spherical shape and/or adopt different morphologies [36]. Above a certain concentration known as the critical aggregation concentration, the micelles can self-assemble into different structures, e.g., rods, disks, spheres, bilayers or vesicles. 




Figure 5. Cont. 

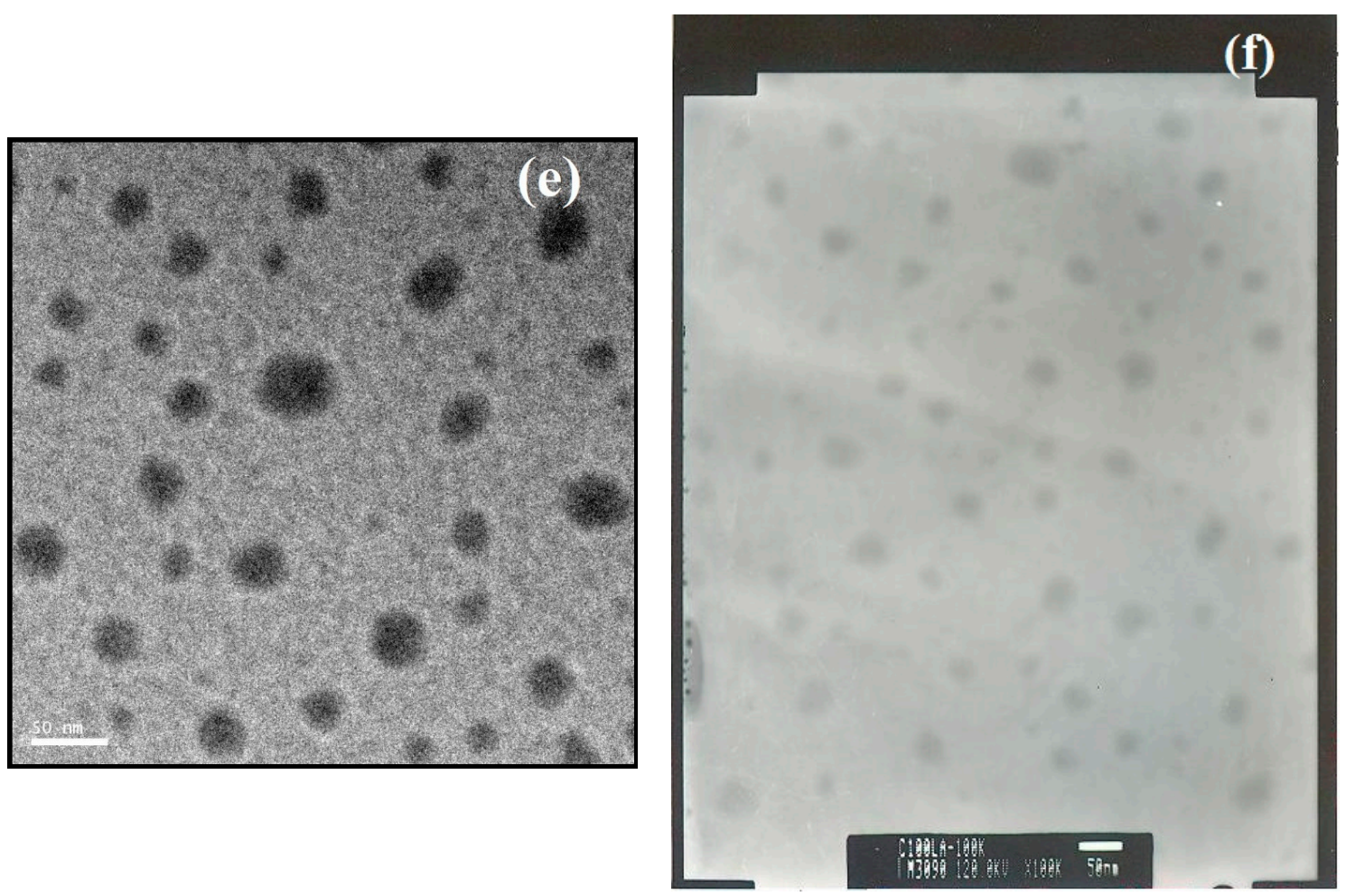

Figure 5. Transmission electron microscopy (TEM) images for the micelles without LA (a-c): $M_{20}$, $\mathrm{MC}_{50}$, and $\mathrm{MC}_{100}$, respectively; the micelles loaded with LA (d-f): $\mathrm{MC}_{20} \mathrm{LA}, \mathrm{MC}_{50} \mathrm{LA}$, and $\mathrm{MC}_{100} \mathrm{LA}$, respectively. The scale bar is $50 \mathrm{~nm}$ except for Figure $5 \mathrm{~d}$ in which it is $200 \mathrm{~nm}$.

\subsection{Drug Loading Content of LA in Micelle}

The loading content of LA in LA-loaded micelles is shown in Table 4. LA encapsulated in the micelles was determined by HPLC after being derived from lauric acid naphthacyl ester, which was detected by fluorescent detector of HPLC. As shown in Table 4, the micelle concentration was obtained by freeze drying. After that, the as-prepared micelles were weighed to calculate the yield of preparation. It reflects the yield of the preparation method of micelles. One can observe that the concentration of micelles for $\mathrm{MC}_{100} \mathrm{LA}$ was one order of magnitude lower than that for the other two micelles. This could be attributed to the preparation of the micelles and the solubility of LA in the polymer segment of PCL [19]. Compared with dialysis, the thin-film hydration and ultra-sonication used in the present study can obtain micelles in a short period of time. PCL also has been known as a semi-crystalline polymer. The increased molecular weight of PCL in PCECs led to increased core crystallinity. As a result, the solubility of LA in that micelle was reduced [37]. In Table 4, the DLCs for $\mathrm{MC}_{20} \mathrm{LA}, \mathrm{MC}_{50} \mathrm{LA}$, and $\mathrm{MC}_{100} \mathrm{LA}$ were $3.27 \%, 9.75 \%$, and $15.42 \%$, respectively. Apparently, the DLCs were dependent on the composition of PCL-PEG-PCL copolymers. The LA was physically encapsulated into the micelles due to the hydrophobic interactions between LA and the core segment of PCL. Hence, the DLC was affected by the interactions between LA and PCL, the crystallinity of PCL and the hydrogen bond interactions [34]. In our study, the favorable interactions between PCL and LA were enhanced in the cores of the micelles, leading to an increase in the DLC of LA. Furthermore, $\mathrm{MC}_{50}$ LA prepared with $10 \mathrm{mg}$ of PCL-PEG-PCL and $2 \mathrm{mg}$ of LA reached the highest concentration of encapsulated LA (e.g., $323.75 \mu \mathrm{g} / \mathrm{mL}$ ), which required larger space to accommodate LA than did the other two micelles. Therefore, the particle size of $\mathrm{MC}_{50}$ after loading LA did not apparently change compared with those of $\mathrm{MC}_{20}$ and $\mathrm{MC}_{100}$. 
Table 4. Concentration of LA loaded micelles and drug loading content.

\begin{tabular}{cccc}
\hline Micelle & $\begin{array}{c}\text { Concentration of LA in micelles }^{\mathbf{a}} \\
(\boldsymbol{\mu} \mathbf{g} / \mathbf{m L})\end{array}$ & $\begin{array}{c}\text { Concentration of micelles }^{\mathbf{b}} \\
(\mathbf{m g} / \mathbf{m L})\end{array}$ & $\begin{array}{c}\text { Drug loading content }^{\mathbf{c}} \\
\mathbf{( \% )}\end{array}$ \\
\hline $\mathrm{MC}_{20} \mathrm{LA}$ & $172.24 \pm 6.19$ & $5.27 \pm 0.06$ & $3.27 \pm 0.15$ \\
$\mathrm{MC}_{50} \mathrm{LA}$ & $323.75 \pm 15.33$ & $3.43 \pm 0.7$ & $9.75 \pm 2.35$ \\
$\mathrm{MC}_{100} \mathrm{LA}$ & $105.30 \pm 12.56$ & $0.7 \pm 0.1$ & $15.42 \pm 4.02$ \\
\hline
\end{tabular}

${ }^{\text {a }}$ Concentration of encapsulated LA measured by reversed-phase high performance liquid chromatography (HPLC); ${ }^{b}$ as-prepared micelles containing the polymer and LA were freeze-dried and weighed; ${ }^{c}$ the drug loading content calculated by equation: $\frac{\text { amount of encapsulated LA }}{\text { amount of polymer }+\mathrm{LA}} \times 100 \%$.

\subsection{Minimum Inhibitory Concentration}

Figure 6 represents the MICs of free LA and various LA-loaded micelles. The MICs of LA-loaded micelles were compared with those of free LA to evaluate the effect of LA on the inhibition of P. acnes growth. As shown in Figure 6, the lowest concentration to prevent bacterial growth in free LA was $20 \mu \mathrm{g} / \mathrm{mL}$, which was lower than that of BPO $(100 \mu \mathrm{g} / \mathrm{mL})$ [38]. The same value of MIC was found for both $\mathrm{MC}_{20} \mathrm{LA}$ and $\mathrm{MC}_{50} \mathrm{LA}$. This result proved that $\mathrm{LA}$ is a promising antibacterial to inhibit the growth of P. acnes. The DLCs for the three micelles were closely related to the MICs. The bacteria were cultured in the liquid medium to determine the MICs. We found that the bacteriostatic action was significant for $\mathrm{MC}_{100} \mathrm{LA}$, whereas $\mathrm{MC}_{20} \mathrm{LA}$ and $\mathrm{MC}_{50} \mathrm{LA}$ did not effectively inhibit the growth of P. acnes. Notably, only $10 \mu \mathrm{g} / \mathrm{mL} \mathrm{MC}_{100} \mathrm{LA}$ was required to achieve the same inhibitory effect of free LA. This was because the drug loading content was higher, leading to an improved antibacterial effect. According to the literature, the water solubility of LA is $4.81 \mu \mathrm{g} / \mathrm{mL}$ [39], and thus the payloads of the PCEC micelles were 35.8, 67.3, and 21.9-fold for $\mathrm{MC}_{20} \mathrm{LA}, \mathrm{MC}_{50} \mathrm{LA}$, and $\mathrm{MC}_{10} \mathrm{LA}$, respectively, relative to free LA in water. These data showed the advantage of the particulate-based drug delivery systems to increase the solubility of water-insoluble drugs.

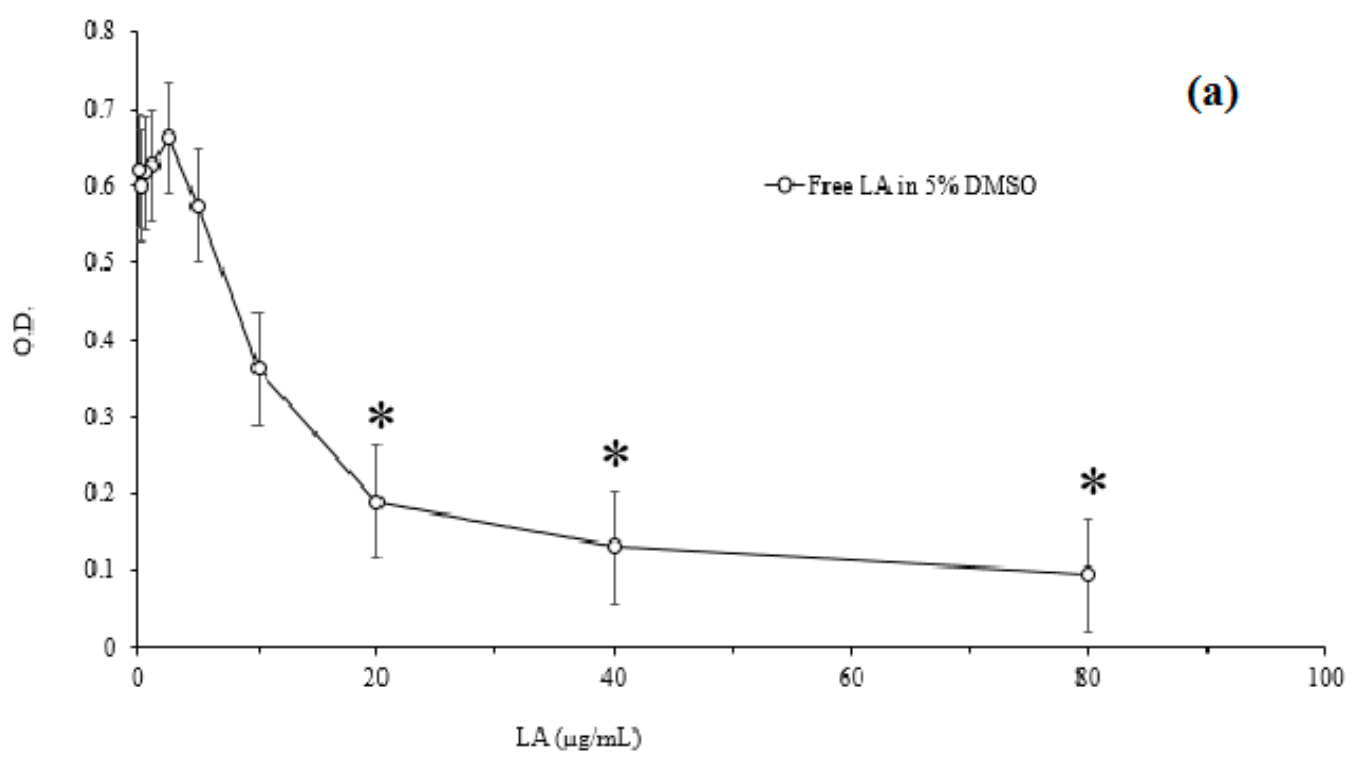

Figure 6. Cont. 


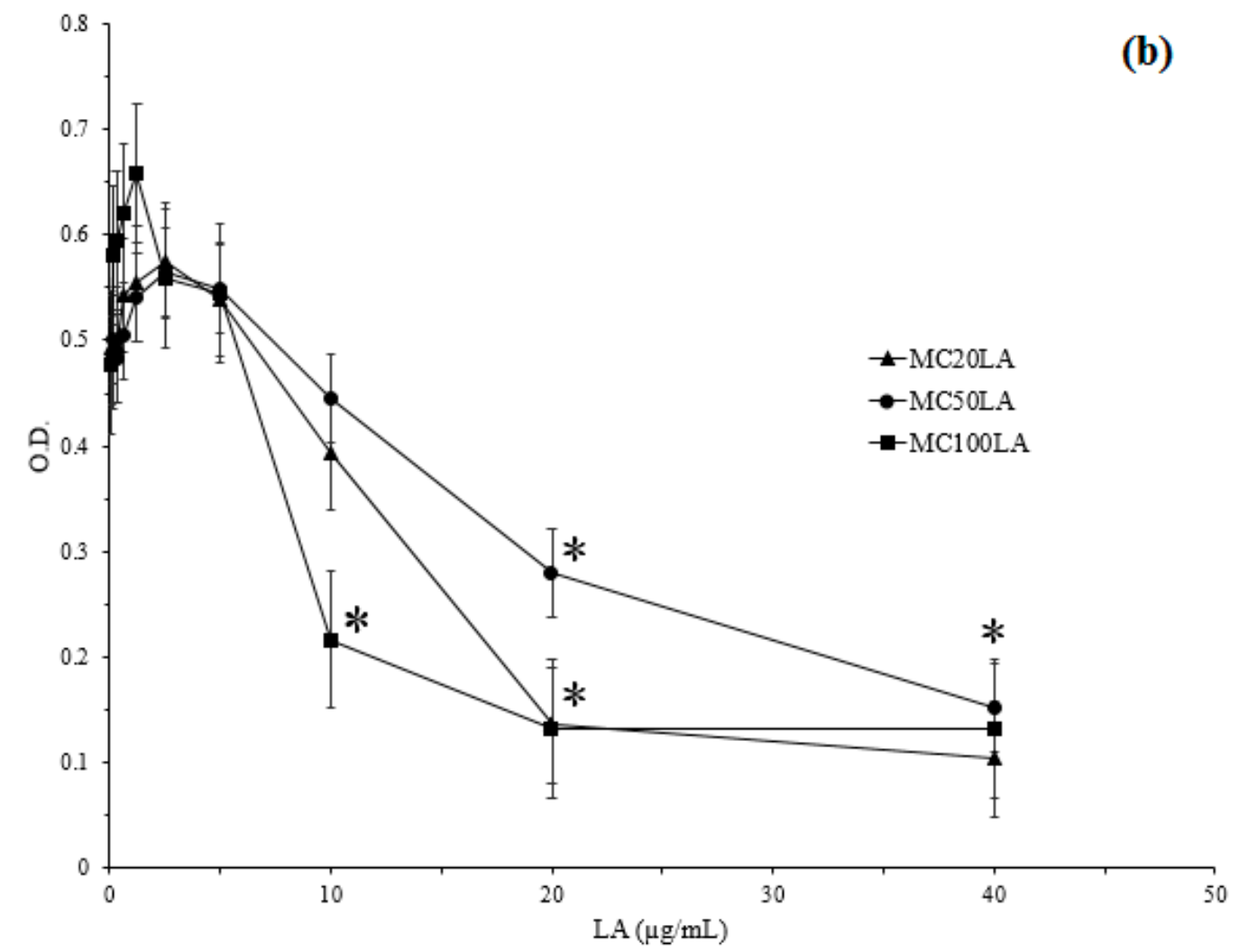

Figure 6. The minimum inhibitory concentration (MIC) assay. (a) MIC of free LA (in 5\% DMSO); (b) MICs of $\mathrm{MC}_{20} \mathrm{LA}, \mathrm{MC}_{50} \mathrm{LA}$, and $\mathrm{MC}_{10} \mathrm{LA}$. The initial concentration of bacteria was $10^{6} \mathrm{CFU} / \mathrm{mL}$; the optical density of bacteria at $600 \mathrm{~nm}$ was measured by ELISA. * indicates significant difference compared with a PBS control by student's $t$-test $(n=3)$.

\subsection{The Minimum Bactericidal Concentration}

P. acnes were diluted with PBS and spotted on Noble agar plates after incubation to determine the CFUs. It has been found that when the concentration of free LA was higher than $80 \mu \mathrm{g} / \mathrm{mL}$ (Figure 7a), over $99.9 \%$ of $P$. acnes were killed. This value was the same as previous studies [19]. The MBCs of $\mathrm{MC}_{20} \mathrm{LA}, \mathrm{MC}_{50} \mathrm{LA}$, and $\mathrm{MC}_{100} \mathrm{LA}$ were all $40 \mu \mathrm{g} / \mathrm{mL}$ (Figure $7 \mathrm{~b}$ ), which revealed that LA-loaded micelles produce many potent bactericidal effects than does free LA on P. acnes. This was due to over 20-fold more LA loaded onto the micelles compared with free LA in PBS [3]. These results again displayed the advantage of the high payload of LA in the micelles when co-cultured with P. acnes. Figure 8 displays the colonies of $P$. acnes grown on RCM when co-cultured with the PCEC micelles. It was observed that $20 \mu \mathrm{g} / \mathrm{mL} \mathrm{MC}_{100}$ LA could partially kill bacteria, whereas the other micelles at the same concentration remained non-effective (Figure 8d). This showed the relatively stronger antibacterial effect among the other micelle formulations. This performance was also observed via the MIC experiment in Section 3.4. This could be explained because $M_{100} L A$ was characterized as the highest loading content. Furthermore, all of the micellar formulations carried a lethal dosage of LA against $P$. acnes.

Since LA was found to inhibit the growth of skin commensal P. acnes in 2009 [3], various dosage forms have been developed. For example, Silva et al. reported solid lipid nanoparticles containing retinoic acid and LA for the topical treatment of acne [40]. Bai and Hsueh used tea tree essential oil encapsulated in silk fibroin/polyvinyl alcohol membrane to manage the inflammation and acne in P. acnes-infected mouse ears [41]. Huang et al. reported that LA not only inhibited the growth of P. acnes but also reduced the inflammation reaction in mice via the NF- $\mathrm{KB}$ and MAP kinase pathways [2]. Overall, the use of free fatty acids in the management of acne vulgaris is a potential approach. A recent 
study in the skin microbiome revealed that Staphylococcus epidermidis can limit the growth of P. acnes via fermentation products, such as free fatty acids [42]. This indicated that our finding in the effect of micellar LA on killing P. acnes is part of the skin microbiome and the engineered nanoparticles; the micellar nanoparticles in this study can exert higher potency of LA toward the bactericidal effect on P. acnes, compared with free LA.
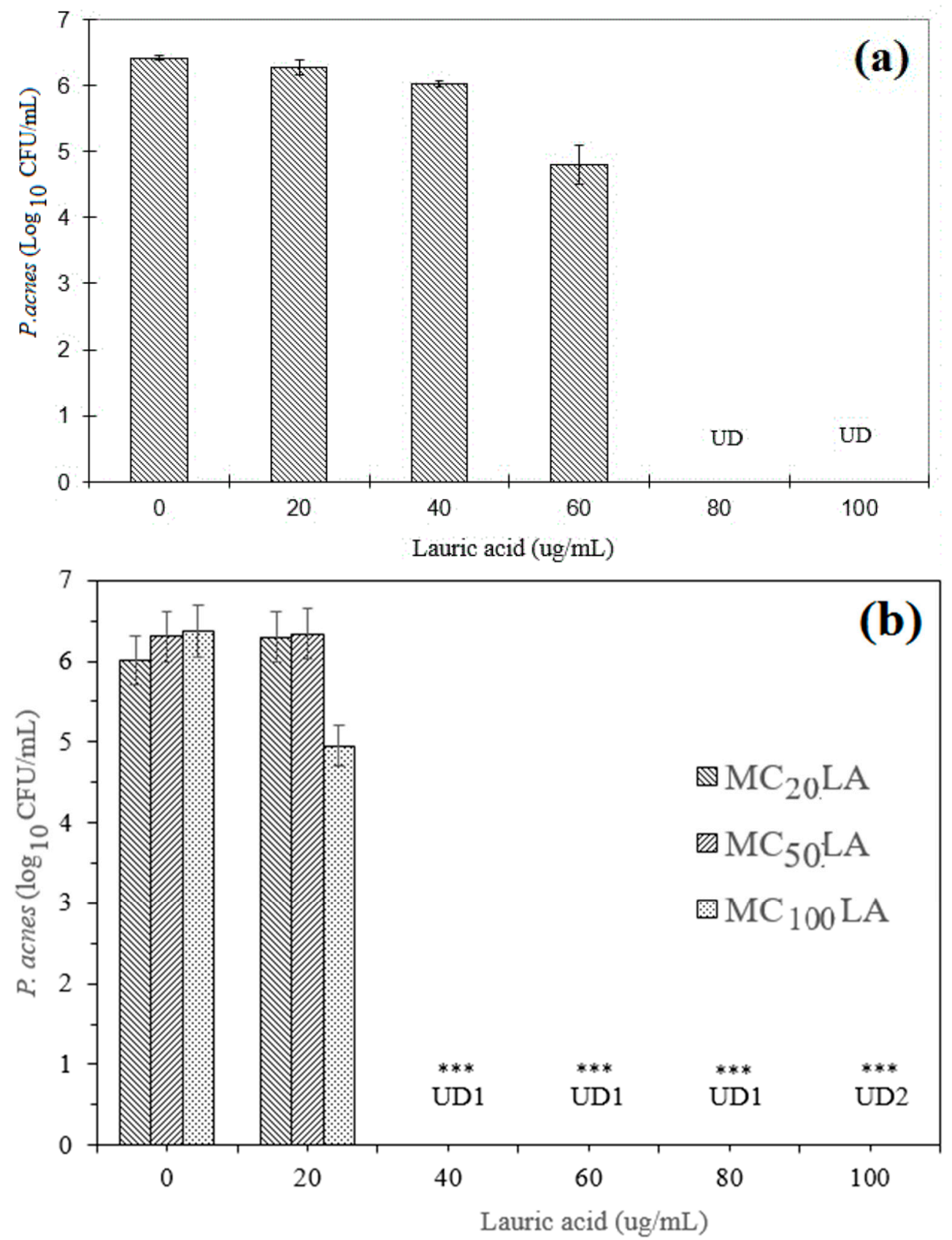

Figure 7. The minimum bactericidal concentration (MBC) assay. UD: no colonies on a Noble agar plate. UD1: there were no colonies for $\mathrm{MC}_{20} \mathrm{LA}, \mathrm{MC}_{50} \mathrm{LA}$, and $\mathrm{MC}_{100} \mathrm{LA}$. UD2: there were no colonies for $\mathrm{MC}_{20} \mathrm{LA}$ and $\mathrm{MC}_{50} \mathrm{LA} ; 100 \mu \mathrm{g} / \mathrm{mL} \mathrm{MC} 100 \mathrm{LA}$ was not tested; (a) LA dissolved in 5\% DMSO or (b) LA-loaded micelles co-cultured with $10^{7} \mathrm{CFU} / \mathrm{mL}$ of $P$. acnes in reinforced clostridial medium (RCM) medium for $5 \mathrm{~h}$ and then spotted on Noble agar plate for $96 \mathrm{~h}$, followed by colony counting; *** indicates significant difference compared to blank micelles made of respective copolymer by student's $t$-test $(n=3)$. 

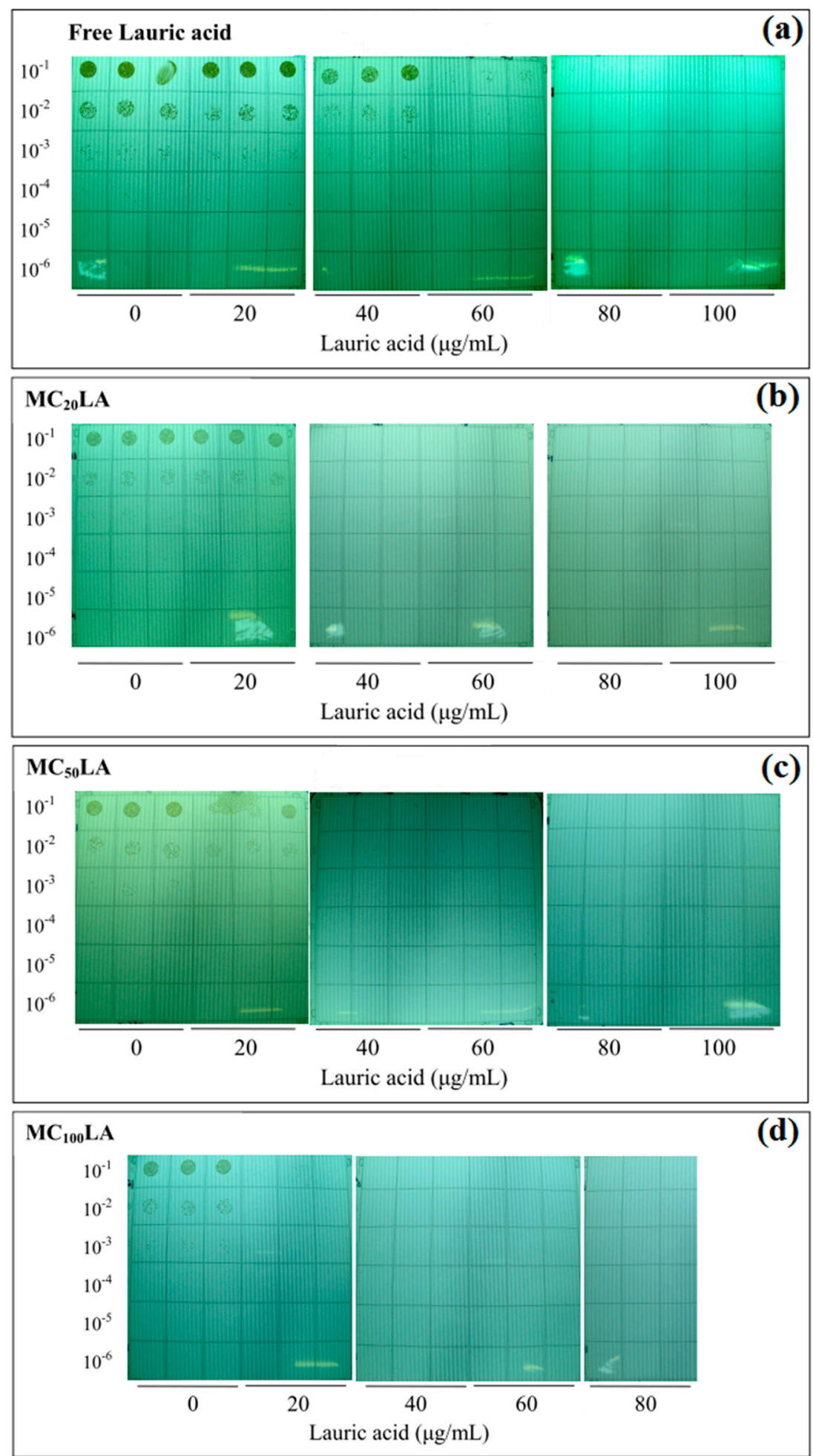

Figure 8. P. acnes grown on RCM in the presence of free LA (a) and LA-loaded micelles (b-d). The images were photographed with a digital camera. For each type of micelle, three columns $(n=3)$ of the bacterial colony were tested. The $Y$ axis indicates the concentration of P. acnes.

\section{Conclusions}

DMSO has been reported to solubilize water-insoluble LA in the treatment of acne vulgaris. It is known that acne is induced by the overgrowth of the skin bacterium P. acnes. However, DMSO can 
induce toxic side effects in skin cells. In this study, the amphiphilic block copolymer PCEC with different molecular weights was successfully synthesized, and LA was loaded in the PCEC micelles using the hydration method. The particle size analysis and zeta potential displayed that LA can be encapsulated in the micellar nanoparticles, and the dosage form of LA-loaded PCEC micelles can replace the use of DMSO as the excipient of LA in the treatment of skin disorders. Moreover, among various LA-loaded micellar nanoparticles, the minimal inhibitory concentration and minimal bactericidal concentration of LA-loaded micelles made of longer hydrophobic PCL segment led to a higher LA payload and exerted the strongest antibacterial effects. Therefore, the promising results of this study merit further study of the efficacy of LA against $P$. acnes infection in future animal studies.

Supplementary Materials: Supplementary Materials can be found at www.mdpi.com/2073-4360/8/9/321/s1.

Acknowledgments: The authors would like to thank the Ministry of Science and Technology of Taiwan for the financial support under contract grant numbers MOST 102-2632-M-033-001-MY3, 104-2221-E-033-068 and 105-2918-I-033-002.

Author Contributions: Thi-Quynh-Mai Tran, Quoc-Hue Pho, Van-Cuong Nguyen and Ching-Yi Cheng for drafting the manuscript; Keng-Lun Chang, Ming-Fa Hsieh and Chun-Ming Huang conducted the experiments and completed the manuscript for final submission.

Conflicts of Interest: The authors declare no conflicts of interest.

\section{References}

1. Dessinioti, C.; Katsambas, A.D. The role of Propionibacterium acnes in acne pathogenesis: Facts and controversies. Clin. Dermatol. 2010, 28, 2-7. [CrossRef] [PubMed]

2. Huang, W.C.; Tsai, T.H.; Chuang, L.T.; Li, Y.Y.; Zouboulis, C.C.; Tsai, P.J. Anti-bacterial and anti-inflammatory properties of capric acid against Propionibacterium acnes: A comparative study with lauric acid. J. Dermatol. Sci. 2014, 73, 232-240. [CrossRef] [PubMed]

3. Yang, D.; Pornpattananangkul, D.; Nakatsuji, T.; Chan, M.; Carson, D.; Huang, C.M.; Zhang, L. The antimicrobial activity of liposomal lauric acids against Propionibacterium acnes. Biomaterials 2009, 30, 6035-6040. [CrossRef] [PubMed]

4. Zouboulis, C.C.; Eady, A.; Philpott, M.; Goldsmith, L.A.; Orfanos, C.; Cunliffe, W.C.; Rosenfield, R. What is the pathogenesis of acne? Exp. Dermatol. 2005, 14, 143-152. [CrossRef] [PubMed]

5. Bojar, R.A.; Holland, K.T. Acne and Propionibacterium acnes. Clin. Dermatol. 2004, 22, 375-379. [CrossRef] [PubMed]

6. Pornpattananangkul, D.; Fu, V.; Thamphiwatana, S.; Zhang, L.; Chen, M.; Vecchio, J.; Gao, W.; Huang, C.M.; Zhang, L. In vivo treatment of Propionibacterium acnes infection with liposomal lauric acids. Adv. Healthc. Mater. 2013, 2, 1322-1328. [CrossRef] [PubMed]

7. Sabetta, J.R.; Rana, V.P.; Vadasdi, K.B.; Greene, R.T.; Cunningham, J.G.; Miller, S.R.; Sethi, P.M. Efficacy of topical benzoyl peroxide on the reduction of Propionibacterium acnes during shoulder surgery. J. Shoulder Elbow Surg. 2015, 24, 995-1004. [CrossRef] [PubMed]

8. Anh, N.T.H.; Cuong, N.V.; Hoang, N.K. Formation of Biodegradable Copolymeric Nanoparticles for Anticancer Drug Delivery. In Proceedings of the Third International Conference on the Development of Biomedical Engineering in Vietnam, Ho Chi Minh City, Vietnam, 11-14 January 2010; Van Toi, V., Khoa, T., Eds.; Springer Berlin Heidelberg: Berlin, Germany, 2010; pp. 203-206.

9. Cuong, N.V.; Li, Y.L.; Hsieh, M.F. In Vitro Biocompatibility of Folate-Decorated Star-Shaped Copolymeric Micelle for Targeted Drug Delivery. In Proceedings of the 5th Kuala Lumpur International Conference on Biomedical Engineering 2011, Kuala Lumpur, Malaysia, 20-23 June 2011; Osman, N., Abas, W., Wahab, A., Ting, H., Eds.; Springer Berlin Heidelberg: Berlin, Germany, 2011; pp. 84-87.

10. Jiang, Z.; Hao, J.; You, Y.; Gu, Q.; Cao, W.; Deng, X. Biodegradable thermogelling hydrogel of P(CL-GL)-PEG-P(CL-GL) triblock copolymer: Degradation and drug release behavior. J. Pharm. Sci. 2009, 98, 2603-2610. [CrossRef] [PubMed] 
11. Khodaverdi, E.; Golmohammadian, A.; Mohajeri, S.A.; Zohuri, G.; Mirzazadeh Tekie, F.S.; Hadizadeh, F. Biodegradable in situ gel-forming controlled drug delivery system based on thermosensitive poly(epsilon-caprolactone)-poly(ethylene glycol)-poly(epsilon-caprolactone) hydrogel. ISRN Pharm. 2012, 2012, 9768-9779.

12. Wei, X.W.; Gong, C.Y.; Gou, M.L.; Fu, S.Z.; Guo, Q.F.; Shi, S.; Luo, F.; Guo, G.; Qiu, L.Y.; Qian, Z.Y. Biodegradable poly( $\varepsilon$-caprolactone)-poly(ethylene glycol) copolymers as drug delivery system. Int. J. Pharm. 2009, 381, 1-18. [CrossRef] [PubMed]

13. Mohanty, A.K.; Jana, U.; Manna, P.K.; Mohanta, G.P. Synthesis and evaluation of MePEG-PCL diblock copolymers: Surface properties and controlled release behavior. Prog. Biomater. 2015, 4, 89-100. [CrossRef] [PubMed]

14. Hallouard, F.; Briancon, S.; Anto, N.; Li, X.; Vandamme, T.; Fessi, H. Influence of diblock copolymer PCL-mPEG and of various iodinated oils on the formulation by the emulsion-solvent diffusion process of radiopaque polymeric nanoparticles. J. Pharm. Sci. 2013, 102, 4150-4158. [CrossRef] [PubMed]

15. Gou, M.; Gong, C.; Zhang, J.; Wang, X.; Wang, X.; Gu, Y.; Guo, G.; Chen, L.; Luo, F.; Zhao, X.; et al. Polymeric matrix for drug delivery: Honokiol-loaded PCL-PEG-PCL nanoparticles in PEG-PCL-PEG thermosensitive hydrogel. J. Biomed. Mater. Res. A 2010, 93, 219-226. [CrossRef] [PubMed]

16. Shin, H.C.; Alani, A.W.G.; Rao, D.A.; Rockich, N.C.; Kwon, G.S. Multi-drug loaded polymeric micelles for simultaneous delivery of poorly soluble anticancer drugs. J. Control. Release 2009, 140, 294-300. [CrossRef] [PubMed]

17. Aguiar, J.; Carpena, P.; Molina-Bolívar, J.A.; Carnero Ruiz, C. On the determination of the critical micelle concentration by the pyrene 1:3 ratio method. J. Colloid Interface Sci. 2003, 258, 116-122. [CrossRef]

18. Rioux, V.C.D.; Bouriel, M.; Legrand, P. High performance liquid chromatography of fatty acids as naphthacyl derivatives. Analusis 1999, 27, 186-193. [CrossRef]

19. Nakatsuji, T.; Kao, M.C.; Fang, J.Y.; Zouboulis, C.C.; Zhang, L.; Gallo, R.L.; Huang, C.M. Antimicrobial property of lauric acid against Propionibacterium acnes: Its therapeutic potential for inflammatory acne vulgaris. J. Investig. Dermatol. 2009, 129, 2480-2488. [CrossRef] [PubMed]

20. Rodríguez-Tudela, J.L.; Barchiesi, F.; Bille, J.; Chryssanthou, E.; Cuenca-Estrella, M.; Denning, D.; Donnelly, J.P.; Dupont, B.; Fegeler, W.; Moore, C.; et al. Method for the determination of minimum inhibitory concentration (MIC) by broth dilution of fermentative yeasts. Clin. Microbiol. Infect. 2003, 9, i-viii. [CrossRef]

21. Holla, G.; Yeluri, R.; Munshi, A.K. Evaluation of minimum inhibitory and minimum bactericidal concentration of nano-silver base inorganic anti-microbial agent (Novaron $\left({ }^{\circledR}\right)$ ) against streptococcus mutans. Contemp. Clin. Dent. 2012, 3, 288-293. [PubMed]

22. Gong, C.Y.; Shi, S.; Wu, L.; Gou, M.; Yin, Q.; Guo, Q.; Dong, P.; Zhang, F.; Luo, F.; Zhao, X.; et al. Biodegradable in situ gel-forming controlled drug delivery system based on thermosensitive PCL-PEG-PCL hydrogel: Part 1-Synthesis, characterization, and acute toxicity evaluation. J. Pharm. Sci. 2009, 98, 4684-4694. [CrossRef] [PubMed]

23. Gong, C.Y.; Wu, Q.J.; Dong, P.W.; Shi, S.; Fu, S.Z.; Guo, G.; Hu, H.Z.; Zhao, X.; Wei, Y.Q.; Qian, Z.Y. Acute toxicity evaluation of biodegradable in situ gel-forming controlled drug delivery system based on thermosensitive PEG-PCL-PEG hydrogel. J. Biomed. Mater. Res. B 2009, 91, 26-36. [CrossRef] [PubMed]

24. Tamboli, V.; Mishra, G.P.; Mitra, A.K. Novel pentablock copolymer (PLA-PCL-PEG-PCL-PLA) based nanoparticles for controlled drug delivery: Effect of copolymer compositions on the crystallinity of copolymers and in vitro drug release profile from nanoparticles. Colloid Polym. Sci. 2013, 291, 1235-1245. [CrossRef] [PubMed]

25. Tamboli, V.M. Pentablock Copolymers Based Controlled Release Formulations of Small and Macromolecules for Ophthalmic Applications. Ph.D. Thesis, School of Pharmacy and Department of Chemistry, University of Missouri-Kansas City, Kansas City, MI, USA, 2012.

26. Liu, C.B.; Gong, C.Y.; Huang, M.J.; Wang, J.W.; Pan, Y.F.; Zhang, Y.D.; Li, G.Z.; Gou, M.L.; Wang, K.; Tu, M.J.; et al. Thermoreversible gel-sol behavior of biodegradable PCL-PEG-PCL triblock copolymer in aqueous solutions. J. Biomed. Mater. Res. B 2008, 84, 165-175. [CrossRef] [PubMed]

27. Piao, L.; Dai, Z.L.; Deng, M.X.; Chen, X.S.; Jing, X.B. Synthesis and characterization of PCL/PEG/PCL triblock copolymers by using calcium catalyst. Polymer 2003, 44, 2025-2031. [CrossRef]

28. Zhang, X.; Jackson, J.K.; Burt, H.M. Determination of surfactant critical micelle concentration by a novel fluorescence depolarization technique. J. Biochem. Biophys. Methods 1996, 31, 145-150. [CrossRef] 
29. Hu, Y.; Jiang, X.; Ding, Y.; Zhang, L.; Yang, C.; Zhang, J.; Chen, J.; Yang, Y. Preparation and drug release behaviors of nimodipine-loaded poly(caprolactone)-poly(ethylene oxide)-polylactide amphiphilic copolymer nanoparticles. Biomaterials 2003, 24, 2395-2404. [CrossRef]

30. Ahmad, Z.; Shah, A.; Siddiq, M.; Kraatz, H.-B. Polymeric micelles as drug delivery vehicles. RSC Adv. 2014, 4, 17028-17038. [CrossRef]

31. Hoang, B.; Lee, H.; Reilly, R.M.; Allen, C. Noninvasive monitoring of the fate of ${ }^{111}$ In-labeled block copolymer micelles by high resolution and high sensitivity microSPECT/CT imaging. Mol. Pharm. 2009, 6, 581-592. [CrossRef] [PubMed]

32. Govender, T.; Stolnik, S.; Garnett, M.C.; Illum, L.; Davis, S.S. PLGA nanoparticles prepared by nanoprecipitation: Drug loading and release studies of a water soluble drug. J. Control Release 1999, 57, 171-185. [CrossRef]

33. Hu, Y.; Jiang, X.; Ding, Y.; Zhang, L.; Yang, C.; Zhang, J.; Chen, J.; Yang, Y. Degradation behavior of poly( $\varepsilon$-caprolactone)- $b$-poly(ethylene glycol)-b-poly( $\varepsilon$-caprolactone) micelles in aqueous solution. Biomacromolecules 2004, 5, 1756-1762. [CrossRef] [PubMed]

34. Kumari, A.; Singla, R.; Guliani, A.; Yadav, S.K. Nanoencapsulation for drug delivery. EXCLI J. 2014, 13, 265-286. [PubMed]

35. Trivedi, R.; Kompella, U.B. Nanomicellar formulations for sustained drug delivery: Strategies and underlying principles. Nanomedicine 2010, 5, 485-505. [CrossRef] [PubMed]

36. Allan, S.; Hoffman, J.Y.L. Handbook of Materials for Nanomedicine; Pan Stanford: Singapore, 2010; Volume 1, p. 868.

37. Glavas, L.; Olsén, P.; Odelius, K.; Albertsson, A.-C. Achieving micelle control through core crystallinity. Biomacromolecules 2013, 14, 4150-4156. [CrossRef] [PubMed]

38. Webster, G.F.; Rawlings, A.V. Acne and Its Therapy (Basic and Clinical Dermatology), 1st ed.; CRC Press: Boca Raton, FL, USA, 2007.

39. Dannenfelser, R.-M.; Yalkowsky, S.H. QSAR in Environmental toxicology database of aqueous solubility for organic non-electrolytes. Sci. Total Environ. 1991, 109, 625-628. [CrossRef]

40. Elton, L.S.; Lidiane, A.A.; Mariana, J.V.T.; Maria, I.Y.; Rodrigo, L.O.; Luis, M.F.; Maria, A.R.C.; Simone, G.S.; Gisele, A.C.G.; Ricardo, J.A.; et al. Solid lipid nanoparticles loaded with retinoic acid and lauric acid as an alternative for topical treatment of acne vulgaris. J. Nanosci. Nanotechnol. 2014, 14, 1-8.

41. Bai, M.Y.; Hsueh, Y.W. Evaluation of silk fibroin protein/poly(vinyl alcohol) transparent membranes as prospective patch for acne care. J. Bioact. Compat. Polym. 2015, 30, 490-508. [CrossRef]

42. Wang, Y.; Kuo, S.; Shu, M.; Yu, J.; Huang, S.; Dai, A.; Two, A.; Gallo, R.L.; Huang, C.M. Staphylococcus epidermidis in the human skin microbiome mediates fermentation to inhibit the growth of Propionibacterium acnes: Implications of probiotics in acne vulgaris. Appl. Microbiol. Biotechnol. 2014, 98, 411-424. [CrossRef] [PubMed]

(C) 2016 by the authors; licensee MDPI, Basel, Switzerland. This article is an open access article distributed under the terms and conditions of the Creative Commons Attribution (CC-BY) license (http://creativecommons.org/licenses/by/4.0/). 